Published in final edited form as:

Cancer Nurs. 2014 ; 37(4): 241-251. doi:10.1097/NCC.0b013e3182a40d8d.

\title{
Predictors of Stage of Adoption for Colorectal Cancer Screening Among African American Primary Care Patients
}

\author{
Dr. Hsiao-Lan Wang, PhD, RN, CMSRN, HFS, \\ University of South Florida College of Nursing, Tampa, Florida
}

Ms. Shannon M. Christy, MA,

Department of Psychology, Purdue University School of Science, Indiana University-Purdue University Indianapolis, Indianapolis, Indiana

\section{Dr. Celette S. Skinner, PhD,}

University of Texas Southwestern Medical Center, Harold C. Simmons Cancer Center, Dallas, Texas

\section{Dr. Victoria L. Champion, PhD, RN, FAAN,} Indiana University School of Nursing, Indianapolis, Indiana: Indiana University Simon Cancer Center, Indianapolis, Indiana

Dr. Jeffrey K. Springston, PhD, University of Georgia, Grady College of Journalism and Mass Communication, Athens, Georgia

Dr. Susan M. Perkins, PhD, Indiana University Simon Cancer Center, Indianapolis, Indiana: Indiana University School of Medicine, Indianapolis, Indiana

Dr. Yan Tong, PhD, Indiana University School of Medicine, Indianapolis, Indiana

Ms. Connie Krier, BS,

Indiana University School of Nursing, Indianapolis, Indiana

Ms. Netsanet Gebregziabher, MS, and Indiana University School of Medicine, Indianapolis, Indiana

Dr. Susan M. Rawl, PhD, RN, FAAN

Indiana University School of Nursing, Indianapolis, Indiana: Indiana University Simon Cancer Center, Indianapolis, Indiana

\begin{abstract}
Background-Compared with other racial groups, African Americans have the highest colorectal cancer (CRC) incidence and mortality rates coupled with lower screening rates.
\end{abstract}

Correspondence: Hsiao-Lan Wang, PhD, RN, CMSRN, HFS, University of South Florida College of Nursing, 12901 Bruce B. Downs Blvd., MDC22, Tampa, FL 33612 (hwang5 @ health.usf.edu).

Conflicts of Interest: The authors have no conflict of interest to disclose. 
Objective-Our study examined the predictors of stage of adoption for fecal occult blood testing (FOBT) and colonoscopy among African American primary care patients who were non-adherent to published screening guidelines.

Methods-Baseline data $(\mathrm{N}=815)$ in a randomized clinical trial were analyzed. Participants were categorized into precontemplation, contemplation, and preparation stages for FOBT and colonoscopy. Predictor variables were demographics, clinical variables, CRC health beliefs and knowledge, and social support. Hierarchical modeling was to identify significant predictors of stage of adoption.

Results-Older, male, Veterans Affairs participants and those with higher perceived selfefficacy, family/friend encouragement, and a provider recommendation had higher odds of being at a more advanced stage of adoption for FOBT. Patients with a history of cancer and higher perceived barriers had higher odds of being at an earlier stage of adoption for FOBT. Predictors of more advanced stage of adoption for colonoscopy included higher perceived benefits, higher perceived self-efficacy, family/friend encouragement, and a provider recommendation for colonoscopy. Higher income ( $>30 \mathrm{~K}$ vs. $<15 \mathrm{~K}$ ) was predictive of earlier stage of adoption for colonoscopy.

Conclusions-Enhancing self-efficacy, encouragement from family and friends, and provider recommendations are important components of interventions to promote CRC screening.

Implications for Practice-Nurses can utilize knowledge of the characteristics associated with stage of adoption to educate and motivate their African American primary care patients to complete CRC screening tests.

\section{Keywords}

Colorectal cancer; screening; stage of adoption; health beliefs

Colorectal cancer (CRC) remained the third most commonly diagnosed cancer and the third leading cause of cancer deaths in the United States in 2012. ${ }^{1}$ African Americans have the highest CRC incidence and mortality rates of all racial groups. ${ }^{2}$ This racial disparity has been attributed to limited access to quality care, failure of providers to recommend screening, and low rates of participation when screening is offered. ${ }^{3}$ Differences in genetics and in tumor characteristics among African Americans may also contribute to poor CRC outcomes. ${ }^{3,4}$

Studies have demonstrated the effectiveness of screening in reducing CRC incidence and mortality. ${ }^{5,6}$ Individuals are at average risk for developing CRC if they have no known risk factors other than age, and screening guidelines recommend screening begin at age 50.7 There are multiple CRC screening test options, but fecal occult blood test (FOBT) and colonoscopy are the most commonly used CRC screening tests. ${ }^{8}$

Although CRC screening rates have improved over the last two decades, they remain suboptimal for all Americans and are lowest among racial and ethnic minorities. The most recent data show that rates of CRC screening with FOBT or endoscopy (sigmoidoscopy or colonoscopy) among Non-Hispanic Caucasians 50 years of age and older was $61.5 \%$, but only 55.5\% among Non-Hispanic African Americans. ${ }^{7}$ Given their higher CRC incidence 
and mortality rates, there is an urgent need to increase screening participation among African Americans.

Primary care practice is often the first place for delivery of CRC screening services including education, recommendations, and prescriptions for screening tests. ${ }^{9}$ Standard educational materials to promote CRC screening have been disappointingly unsuccessful. ${ }^{10}$ Multiple studies suggest that theory-based tailored messages to increase screening are more likely to be successful, especially those tailored to stage of adoption. ${ }^{11-13}$ In order to understand how to promote CRC screening behavior among primary care African American patients, we analyzed baseline data from a large randomized controlled trial (RCT) that tested a computer-delivered tailored intervention to promote CRC screening among African American primary care patients who were non-adherent to current screening guidelines. ${ }^{14}$

\section{Conceptual Framework}

Our conceptual framework includes stage of adoption as the outcome variable and four domains of predictor variables (See Figure). The Transtheoretical Model (TTM) describes behavior change as a dynamic process through which individuals move in a series of discrete phases, or stages, of adoption - from precontemplation to action to maintenance. ${ }^{15}$ In our study, we enrolled only African American primary care patients who were not in the action or maintenance stages for CRC screening. Therefore, at baseline, participants were categorized into one of three stages of adoption for each CRC screening test separately: precontemplation, contemplation, and preparation. The criteria for defining stages of adoption for FOBT and colonoscopy are shown in Table 1.

The predictor variables were selected from the empirical evidence. Relationships between these variables and CRC screening behaviors (action stage) have been found in previous studies. ${ }^{8}, 12,16-18$ We grouped the predictor variables based on their conceptual similarity. The four domains of predictor variables include demographic, clinical, CRC health beliefs and knowledge, and social support variables. They are arranged from non-modifiable, individual factors (i.e., demographics, clinical variables) to modifiable, interpersonal factors (i.e., CRC health beliefs and knowledge, social support). Our study examined predictors of stage of adoption for CRC screening among African American primary care patients. We conducted these analyses to answer the following research questions. Among African American primary care patients who were non-adherent to CRC screening guidelines:

1. Which demographic, clinical, CRC health beliefs and knowledge, and social support variables predict stage of adoption for FOBT, and what are the relative contributions of each domain to the total variance explained?

2. Which demographic, clinical, CRC health beliefs and knowledge, and social support variables predict stage of adoption for colonoscopy, and what are the relative contributions of each domain to the total variance explained?

\section{Methods}

Our descriptive analysis used baseline data from 817 primary care patients enrolled in the

RCT to test a computer-delivered tailored intervention to promote CRC screening. ${ }^{14} \mathrm{~A}$ total 
of 817 subjects were enrolled in the RCT; however, the baseline stage of adoption was unavailable for two different participants for each test (FOBT: $n=815$; colonoscopy: $n=815$ ). Participants were recruited from 11 Midwestern urban primary care clinics: 5 communitybased clinics affiliated with a safety-net hospital, 1 university-affiliated family medicine clinic, 1 clinic affiliated with a large, multi-hospital health care system, and 4 Veterans Affairs (VA) clinics. Recruiters identified potentially eligible participants from clinic databases and obtained health care provider approval prior to contact. Patients with upcoming primary care visits were mailed an introductory letter (signed by their provider), a recruitment brochure explaining the study, and an informed consent document. Within one week of this mailing, patients who had not called the research office to decline participation were contacted by a recruiter, who assessed eligibility, explained the study, answered questions, and obtained verbal consent. Patients were eligible if they were 51 to 80 years of age, English-speaking, self-identified as Black or African American, and were currently non-adherent to CRC screening guidelines (no FOBT in the past 12 months, no colonoscopy in the past 10 years, and no sigmoidoscopy in the past 5 years). Exclusion criteria included having a personal history of $\mathrm{CRC}$ or adenomatous polyps requiring surveillance colonoscopy; any medical condition that prohibited CRC screening; or a cognitive, speech, or hearing impairment.

Eligible patients who consented to participate were scheduled for a 30 minute baseline interview. Data were collected by trained interviewers using a computer-assisted telephone interview system. All study procedures were HIPAA Privacy and Security Rules compliant and were approved by the Indiana University Institutional Review Board (IRB) prior to implementation.

\section{Measures}

Outcome Variable-The outcome variable -- stage of adoption for CRC screening-- was assessed separately for FOBT and colonoscopy via an adapted version of Prochaska and DiClemente's Transtheoretical Model. ${ }^{19}$ For each test, three items assessed whether participants: 1) had the test within the recommended time frame; 2) were planning to complete the test in the next 6 months; and 3) had an FOBT kit at home or a colonoscopy appointment scheduled. If a participant responded "No" to all three items, s/he was categorized into the precontemplation stage for that test. If the answer to the first item was "No," the second item was "Yes" and the third item was "No," s/he was categorized into the contemplation stage for that test. If the answer to the first item was "No," the second item was "Yes" and the third item was "Yes," s/he was categorized into the preparation stage for that test (Table 1).

Predictor Variables-The four domains of predictor variables were assessed as follows. Demographics including age, gender, education, employment, income, and health insurance were obtained via self-report. Recruitment sites were dichotomized into VA clinics or nonVA sites. The VA Healthcare System launched quality improvement initiatives to increase CRC screening after our RCT was initiated, ${ }^{20}$ so we accounted for this difference in our analysis plan. The non-VA clinics were all part of an urban safety net hospital system that provided primary care for low income, predominantly minority populations. 
Clinical variables included body mass index (BMI), family history of CRC, personal history of cancer (other than CRC), and objective risk for CRC. BMI was calculated from selfreported body weight and height. Family history of CRC and personal history of cancer were assessed using two single items. Objective risk for CRC was coded as "average risk" for those who had no CRC risk factors other than age and as "increased risk" for participants who had: 1) more than one first degree blood relative with CRC; or 2) one first degree blood relative who was diagnosed with CRC before the age of $60 .{ }^{21}$

Health beliefs and knowledge included CRC perceived risk, perceived benefits, perceived barriers, self-efficacy, cancer fatalism, and knowledge. Perceived risk (susceptibility) was assessed using two measures: a 5 item Likert-type scale to measure perceived risk ${ }^{22}$ and a single item measure of perceived (age-adjusted) comparative risk. ${ }^{23}$ The perceived risk scale used these response options: 1 = "very likely" to 4 ="very unlikely" to assess participants' beliefs about how likely they were to get CRC in the next 5 years, 10 years, or sometime during their lifetime. The Cronbach's alpha for this 5 item scale was 0.79 in our study. Perceived comparative risk was assessed by "Compared to other (men/women) your age, would you say your chance of getting colon cancer in the next ten years is...?". ${ }^{23}$ Response options were "lower," "about the same," or "higher than others my age."

Perceived benefits, barriers, and self-efficacy were measured for FOBT and colonoscopy separately using valid and reliable Likert scales with four response options. ${ }^{24}$ For perceived benefits and barriers, the response options ranged from $1=$ "strongly disagree" to $4=$ "strongly agree." 24 The FOBT benefits scale contained 3 items (alpha $=0.72$ ), while the colonoscopy benefits scale had 4 items (alpha $=0.69$ ). The FOBT barriers scale contained 9 items (alpha $=0.81$ ); the colonoscopy barriers scale had 15 items (alpha $=0.89$ ). Self-efficacy for CRC screening was measured for FOBT ( 8 items) and colonoscopy (11 items) by asking participants to indicate how sure they were that they could take the steps necessary to complete the test (alpha $=0.88$ for both tests). Four response options were provided ranging from $1=$ "not at all sure" to $4=$ "very sure."

Cancer fatalism was measured using Mayo's modification of the Powe Fatalism Inventory, which assesses the degree to which a person equates cancer with death. ${ }^{25}$ Eleven items were used to assess fear, pessimism, predetermination, and the inevitability of death. Participants selected from four response options ranging from $1=$ "strongly disagree" to $4=$ "strongly agree." Support for validity and reliability has been reported. ${ }^{26}$ The Cronbach's alpha for this scale was 0.86 in our study.

CRC knowledge was measured using 11 questions. Several aspects of knowledge about CRC were assessed, including risk factors, screening test options, and test frequency. Knowledge scores were computed by summing the number of correct responses (possible range: $0-11$ ). This multidimensional instrument had an alpha coefficient of 0.64 and its validity has been previously reported. ${ }^{24}$

Social support included marital status, family/friend encouragement of CRC screening, and provider recommendation for each CRC screening test; all were assessed using single items. Marital status was obtained via self-report. Participants were asked whether family or 
friends had ever encouraged them to have a colon test and whether their provider had ever recommended they have an FOBT and a colonoscopy.

\section{Statistical Analyses}

Descriptive statistics were used to analyze participants' characteristics and the distribution of stage of adoption. For each stage, means and standard deviations were calculated for continuous variables, and frequencies with percentages were calculated for the categorical variables.

Hierarchical modeling was performed based on our proposed conceptual framework to identify predictors of stage of adoption for CRC screening, in which non-modifiable, individual-level variables were entered first (i.e., demographics) followed by clinical variables, and the more modifiable/interpersonal variables were entered later in the following order: CRC health beliefs and knowledge variables, then social support variables. Stage of adoption for FOBT and colonoscopy were modeled separately using ordinal logistic regression to address the research questions. The models assumed that the odds for comparing precontemplation to contemplation and preparation were the same as the odds for comparing precontemplation and contemplation to preparation (the proportional odds assumption). In other words, for each model fit, one set of parameter estimates can be used to describe both comparisons. This is advantageous with regard to interpretation over having two separate sets of estimates. The proportional odds assumption was checked for the models, and it was not found to be violated, which indicated that the ordinal logistic regression model was an appropriate method for this analysis. We modeled the log-odds of being at a more advanced stage of adoption. Thus, when a predictor had an odds ratio greater than 1, this meant that participants with this predictor had higher odds of being at a more advanced stage of adoption or closer to action. On the other hand, when a predictor had an odds ratio of less than 1, this meant that participants with this predictor had higher odds of being at an earlier stage of adoption, thus further away from action.

Post hoc power calculations conducted using the popower and bpower functions of the statistical package $\mathrm{R}^{27}$ show that, given our sample sizes per response (Table 2), we had $82 \%$ and $86 \%$ power, respectively, for FOBT and colonoscopy to detect an odds ratio of 1.5 for a dichotomous predictor that divides the total sample into two equal groups or a continuous predictor split at the median. In comparison, if we had had equal numbers of participants at each stage, our power would have been $88 \%$ and if we had combined preparation with contemplation, our power would have been $82 \%$ in both cases. Thus, there was some loss of power due to the imbalance in percentages of participants at each stage; however, the power was still adequate for our objectives and comparable to (for FOBT) or better than (for colonoscopy) binary logistic regression.

First, bivariate ordinal logistic regression models were used to examine the association of each FOBT stage or colonoscopy stage with each predictor variable in the conceptual framework. Predictor variables with a $p$ value of 0.20 or below from bivariate analyses were selected for the multivariable analysis. Next, multivariable ordinal logistic regression models were used to explore the effects of various predictors on FOBT and colonoscopy stages. Demographic variables were included in the model as predictor variables in the first 
step, then a series of clinical variables, CRC health beliefs and knowledge variables, and social support variables were added to the model in each of the subsequent steps. The final model (Step 4) included all predictor variables. The models were compared sequentially, i.e., Step 2 vs. Step 1, Step 3 vs. Step 2, and Step 4 vs. Step 3 to assess the additive contribution of each block of predictor variables (i.e., demographics, clinical variables, CRC health beliefs and knowledge, and social support) in explaining the variance associated with stage of adoption for FOBT and colonoscopy, respectively. Generalized $\mathrm{R}^{2}$ was reported for each step of the modeling process. All analyses were performed using SAS (Version 9.3, Copyright () 2008 SAS Institute Inc., Cary, NC).

After our RCT was launched, the VA Healthcare System implemented quality improvement initiatives to increase CRC screening. ${ }^{20}$ Whether or not these initiatives could have threatened the validity of our results was uncertain. Therefore, we conducted a post-hoc sensitivity analyses to determine if a VA site was a significant predictor of stage of adoption for either FOBT or colonoscopy. In these analyses, we could examine whether the results from the hierarchical models were substantially changed by excluding the data from the VA participants.

\section{Results}

\section{Sample Description}

Among the total sample (Table 2), the mean age was 57.4 years (range: 51-80), the average education was 12.2 years (range: $3-18$ ), and half of the participants were female (53\%). The majority of participants were not married or partnered (69\%), not currently employed (79\%), not VA patients (80\%), and had no personal history of cancer (92\%) or family history of CRC (74\%). The majority had insurance (89\%) and reported annual incomes of less than $\$ 15,000(59 \%)$. The mean BMI of this group was above 30, indicating that most participants were obese. ${ }^{28}$ For FOBT, 59\% $(\mathrm{n}=484)$ were in precontemplation, $34 \%(\mathrm{n}=277)$ in contemplation, and 7\% $(\mathrm{n}=54)$ in preparation. For colonoscopy, $43 \%(\mathrm{n}=353)$ were in precontemplation, $46 \%(\mathrm{n}=378)$ in contemplation, and $11 \%(\mathrm{n}=84)$ in preparation. The characteristics of participants at each stage, with bivariate analysis results, are shown in Table 2.

\section{Research Question 1: Which demographic, clinical, CRC health beliefs and knowledge, and social support variables predict stage of adoption for FOBT, and what are the relative contributions of each domain to the total variance explained?}

The hierarchical models predicting the FOBT stage are summarized in Table 3. Based on the conceptual model and the results from the bivariate analysis, the demographic variables of age, male gender, income, insurance, and VA site were entered in Step 1. The clinical variables of BMI and personal history of cancer were entered in Step 2; the CRC health beliefs and knowledge variables of CRC perceived risk, perceived FOBT benefits, perceived FOBT barriers, and perceived FOBT self-efficacy were entered in Step 3; and the social support variables of marital status, family or friend encouragement of CRC tests, and provider recommendation of FOBT were entered in Step 4. The final model (Step 4) showed that participants who were older $(\mathrm{OR}=1.04, p=.003)$; male $(\mathrm{OR}=1.70, p=.007)$; seen at a 
VA site $(\mathrm{OR}=2.80, p<.001)$; had greater perceived FOBT self-efficacy $(\mathrm{OR}=1.59, p=$. 007); had family or friend encouragement of CRC testing ( $\mathrm{OR}=1.64, p=.004)$; and had a provider recommendation for FOBT (OR $=2.05, p<.001)$ had higher odds of being at a more advanced stage for FOBT (closer to action). Participants with a personal history of cancer $(\mathrm{OR}=0.37, p=.002)$ and with greater perceived FOBT barriers $(\mathrm{OR}=0.79, p=$. 042) had higher odds of being at an earlier stage of adoption for FOBT. The four blocks of variables combined explained $20.2 \%$ of the variance in FOBT stage. In addition, statistically significant improvements in the amount of variance explained (generalized $\mathrm{R}^{2}$ ) were observed at each step, with greater increases at Step 3 and Step 4 compared to Step 2.

\section{Research Question 2: Which demographic, clinical, CRC health beliefs and knowledge, and social support variables predict stage of adoption for colonoscopy, and what are the relative contributions of each domain to the total variance explained?}

The hierarchical models predicting colonoscopy stage are summarized in Table 4 . The demographic variables of age, education, male gender, income, and insurance were entered in Step 1; the clinical variable BMI was entered in Step 2; the CRC health beliefs and knowledge variables of CRC perceived risk, perceived comparable risk, perceived colonoscopy benefits, perceived colonoscopy barriers, and perceived colonoscopy selfefficacy were entered in Step 3; and the social support variables of family or friend encouragement of CRC tests, and provider recommendation of colonoscopy were entered in Step 4. The final model (Step 4) showed that participants who had: higher perceived colonoscopy benefits ( $\mathrm{OR}=1.56, p<.001)$; higher perceived colonoscopy self-efficacy (OR $=1.66, p<.001)$; family or friend encouragement of CRC tests $(\mathrm{OR}=1.71, p=.001)$; and a provider recommendation for colonoscopy $(\mathrm{OR}=2.47, p<.001)$ had higher odds of being at a more advanced stage for colonoscopy. Compared to participants with incomes of less than $\$ 15,000$, those with incomes greater than $\$ 30,000$ (OR $=0.46, p=.005$ ) had higher odds of being at an earlier stage of adoption for colonoscopy. The four blocks of variables combined explained $16.2 \%$ of the variance of colonoscopy stage. In addition, statistically significant improvements in the amount of variance explained (generalized $\mathrm{R}^{2}$ ) were observed at each step. Again, improvements tended to be higher at Step 3 and Step 4 than at Step 2.

\section{Post Hoc Sensitivity Analyses}

The VA site was a significant predictor of a more advanced stage for FOBT screening. Therefore, post hoc sensitivity analyses were conducted to assess whether the results changed substantively by excluding data from participants seen at the VA site. When data from VA participants were excluded, there were no substantive differences in which variables were significant compared to the primary analyses for FOBT stage. However, the generalized R square was considerably lower at the final step ( 0.202 for the full sample [ $\mathrm{n}$ $=815$ ] vs. 0.115 for the non-VA sample [ $=653])$. We also investigated whether the potential correlation of outcomes within the clinics could be impacting the model results by fitting additional ordinal logistic regression models that adjusted for this correlation using generalized estimating equations. We again found no substantive changes in terms of which predictor variables were significantly related to the outcomes. 


\section{Discussion}

\section{Distribution of Stage of Adoption}

The distribution across stages of adoption in our sample of African American primary care patients was similar to that found in previous studies. For FOBT, the majority of participants were not thinking about this test (i.e., in precontemplation). Similar results were found in studies among lower income community members, ${ }^{29}$ first-degree relatives of people with colorectal cancer, ${ }^{30}$ and insured participants. ${ }^{12}$ For colonoscopy, more participants were in contemplation than in precontemplation in our study. The same results were observed in a previous study among low income African Americans seen in internal medicine clinics. ${ }^{31}$ About $90 \%$ of non-adherent primary care African Americans in our study were not planning to have CRC screening tests in the near future (i.e., were not in preparation). This finding illustrates the challenge of promoting CRC screening behaviors in this population.

\section{Predictors of Stage of Adoption}

The results of this study were consistent with those of other studies identifying predictors of the stage of adoption for FOBT. Factors that consistently have predicted more advanced stage for FOBT, including this study, are older age, ${ }^{30}$ male gender, ${ }^{29}$ fewer perceived barriers, ${ }^{12,30}$ and provider recommendation. ${ }^{29,32}$ In addition, higher perceived self-efficacy predicted more advanced stage for FOBT in our study. Similarly, individuals in the contemplation or action stages for sigmoidoscopy had greater perceived self-efficacy than those in the pre-contemplation stage. ${ }^{12}$ Very few studies have investigated factors related to stage of adoption for colonoscopy. In our study, predictors of being at a more advanced stage of adoption for colonoscopy validated the limited empirical evidence available on CRC screening behaviors: higher perceived benefits, ${ }^{12}$ higher perceived self-efficacy, ${ }^{12}$ and having a provider recommendation ${ }^{29,32,33}$ were predictors of a more advanced stage for colonoscopy.

\section{Social Support}

Few studies have identified the importance of social support for CRC screening, ${ }^{34}$ but our findings indicate that social support may play a significant role in understanding CRC screening behaviors among African American primary care patients. This finding was similar to results from a study investigating mammography behaviors. ${ }^{35}$

Perhaps the most important finding in our study was that family/friend encouragement was the next strongest predictor of advanced stage for both FOBT and colonoscopy, after provider recommendation. In prior research among siblings of CRC patients, family recommendation was found to be predictive of the CRC screening stage of adoption. ${ }^{32}$ Our participants were African American primary care patients. It is possible that the group-level (i.e., African American group) risk of CRC influences individuals' beliefs towards preventive health behaviors ${ }^{36}$ and/or that African American families influence health decisions surrounding CRC screening. ${ }^{34}$ Future interventions to promote CRC screening could be peer support from a family member or friend who has undergone CRC screening. In addition, lay health advisors could promote screening behaviors among families or friend networks in the community. ${ }^{37,38}$ Modes of outreach that have been suggested to promote 
health in the African American community include mobile units, faith-based groups, doorto-door canvasing, and public schools. ${ }^{38}$

As expected, provider recommendation was the most significant predictor of advanced stage of adoption for both FOBT and colonoscopy. In the prior literature, provider recommendation for CRC screening and a variety of additional health care factors (e.g., consistent and/or recent health care usage, receipt of other cancer screenings, provider recommendation for a colonoscopy specifically, taking prescribed medications for 6 months or more, and having previously heard of colonoscopy) have been predictive of higher stage of adoption for CRC screening. ${ }^{32,33}$ Similarly, provider recommendation has been associated with mammography stage of adoption. ${ }^{39}$ Our findings highlight the need for providers to consistently and repeatedly endorse colon cancer screening during primary care visits, track patients who are overdue for screening, and send reminders and educational materials to those who need them. ${ }^{40}$

\section{CRC Health Beliefs}

Health beliefs have been examined in relation to stage of adoption studies for various health behaviors, including mammography, ${ }^{41}$ pap smears, ${ }^{42}$ exercise adoption, ${ }^{43}$ smoking cessation, ${ }^{44}$ dietary fat reduction, ${ }^{44}$ and daily fruit consumption. ${ }^{45}$ Stage of adoption for CRC screening was predicted by perceived barriers, benefits, self-efficacy, and perceived risk of CRC in prior studies. ${ }^{12,46}$ The results from our study suggested that tailoredmessage intervention among African American primary care patients should focus on reducing perceived barriers and improving self-efficacy if FOBT is recommended and improving perceived benefits and self-efficacy if colonoscopy is recommended.

\section{Demographics and Clinical Variables}

For demographics, age, education, and employment have been associated with stage of adoption in prior CRC screening studies. ${ }^{12,}$ 29, 32 The male and older African American primary care patients in our study had higher odds of being at a more advanced stage for FOBT. The homogeneity among our participants (i.e., limited years of education and a low employment rate) possibly contributed to our finding no significant relationships between education or employment and stage of adoption. Not surprisingly, the VA site significantly predicted more advanced stage for FOBT. FOBT is considered the frontline CRC screening test in the VA system and is widely available in VA primary care clinics. ${ }^{20}$ However, based upon the results of our post hoc test excluding the VA site, this did not change the results of the hierarchical models substantively, suggesting that the associations between the predictor variables assessed in this study and stage of adoption were similar between the VA site and non-VA site patients. Participants who had an annual income of more than $\$ 30,000$ had higher odds of being at an earlier stage for colonoscopy when compared with those earning less than $\$ 15,000$ in our study. It is possible that those in the lowest income group had government insurance, which could increase colonoscopy availability and acceptance due to coverage for the test. ${ }^{47}$

For clinical variables, African American primary care patients with a personal history of cancer in our study had higher odds of being at an earlier stage for FOBT. It may be that 
endoscopic CRC tests are more frequently prescribed than FOBT for cancer survivors during specialty physician clinic visits. ${ }^{9}$

\section{Limitations and Strengths}

There are several limitations that should be considered when interpreting these results. It is important to note that the amount of variance explained in stage of adoption was small. It is possible that the health beliefs measured in our study did not completely capture the perceptions of African American primary care patients. For example, the perceived risk was operationalized at the individual level but not at the group level (i.e., among African Americans). Group level perceptions of susceptibility have been associated with perceived benefits of screening among African Americans. ${ }^{36}$ Other constructs that may influence stage of adoption for CRC screening that were not measured in our study include hope (positive attitude toward screening), fear (pain, hospital/doctor, or cancer diagnosis, surgery could spread cancer), medical mistrust (providers do not put patients first, patients are poorlytreated in experiments), and test preference. ${ }^{36,48}$ Another limitation includes the potential for selection bias as these data were from the baseline interview of an intervention study to promote CRC screening. Individuals willing to participate in a CRC screening intervention study might possess different characteristics, beliefs, and attitudes about CRC screening than individuals not willing to participate in such a study. In addition, our results can only be generalized to similar populations of low socioeconomic status (low education level, low income, and unemployed) African Americans who have insurance and are able to access primary care services. Our results may not be replicable among those who are not insured and/or those who have different perspectives on screening. Finally, these analyses used a cross-sectional design to examine stage of adoption. The predictors identified in our study may not have causal relationships with the outcome variable. Stage of adoption was used as the outcome, rather than actual CRC screening behavior because all participants were overdue for screening (i.e., not in the action or maintenance stages) at baseline.

Despite these limitations, our study has a number of strengths. First, this is one of very few studies examining predictors of stage of adoption for CRC screening among African American primary care patients who were currently non-adherent to screening guidelines. The findings from our study could help primary care providers to understand the characteristics of this high risk population and so to develop effective strategies to facilitate adherence to CRC screening recommendations. Second, we measured perceived selfefficacy, perceived benefits, and perceived barriers separately for FOBT and colonoscopy to better capture the information related to these specific screening tests.

\section{Implications for Practice}

The results of our study provide socioculturally relevant information to health care providers who promote CRC screening among African American primary care patients. A self-report questionnaire to assess CRC beliefs and knowledge, family history, and stage of adoption for screening could be added to the pre-visit procedures in primary care clinics. In discussing CRC screening with patients, oncology nurses and Advanced Practice Nurses can tailor education content based on specific sociocultural characteristics, such as encouraging 
discussions with family members or friends who had positive CRC screening experiences, reducing perceived barriers related to CRC and screening tests, highlighting the benefits of screening, and enhancing self-efficacy to complete screening tests by using teach-back methods for how to make appointments and complete screening tests. Nurses can encourage patients to attend group education sessions delivered by racially concordant health care providers in the community. Educational content should be culturally sensitive and developed in collaboration with community members.

Two factors were found to show patients at higher odds of being at an earlier stage of adoption: "a personal history of cancer" related to FOBT and "an annual income of more than $\$ 30,000$ " related to colonoscopy. Primary care nurses need to be aware that patients with history of cancer are more likely at an earlier stage of adoption for FOBT, because they may not receive a recommendation for FOBT. Due to the risk of secondary or metastatic cancer, these individuals instead may receive a recommendation for colonoscopy. ${ }^{9}$ Patients with higher incomes probably have higher co-pays than those with lower incomes. Thus, they may be in an earlier stage of adoption for colonoscopy. Nurses may consider offering them annual FOBT as a CRC screening test option.

\section{Conclusion}

Culturally relevant interventions to promote CRC screening have been identified as an effective approach to reducing CRC disparities among African Americans. ${ }^{49,}{ }^{50}$ The findings from our study illustrate the importance of social support to promote CRC screening in this group. Culturally relevant CRC screening interventions can be delivered by lay health advisors in the African American community along with providers giving recommendations at the primary care clinic. Community-based participatory research designs are suggested to bring community members into the full spectrum of research activity, including problem identification, intervention development, intervention implementation, and post-intervention evaluation. Active engagement of members of African American communities will result in culturally relevant, appropriate, and effective interventions to increase CRC screening and reduce CRC incidence and mortality. Finally, future research among African Americans must include both insured and uninsured populations as well as higher socioeconomic groups to examine other factors that may influence stage of adoption and CRC screening behaviors.

\section{Acknowledgments}

Sources of Funding: Dr. Hsiao-Lan Wang, a post-doctoral fellow, received a grant from the National Institute of Nursing Research (T32 NR007066) at Indiana University School of Nursing to prepare the manuscript. Ms. Shannon M. Christy, a doctoral student, was funded by the Training in Research for Behavioral Oncology and Cancer Control Program (R25 CA117865-06). Dr. Susan M. Rawl received a grant to support this study from the National Cancer Institute (R01 CA115983).

\section{References}

1. Siegel R, Naishadham D, Jemal A. Cancer statistics, 2012. CA Cancer J Clin. 2012; 62(1):10-29. [PubMed: 22237781] 
2. Howlader, N.; Noone, AM.; Krapcho, M., et al. SEER Cancer Statistics Review, 1975-2008. Bethesda, MD: National Cancer Institute; 2011. http://seer.cancer.gov/csr/1975_2008/ [Accessed November 12, 2012]

3. Laiyemo AO, Doubeni C, Pinsky PF, et al. Race and colorectal cancer disparities: healthcare utilization vs different cancer susceptibilities. J Natl Cancer Inst. 2010; 102(8):538-546. [PubMed: 20357245]

4. Agrawal S, Bhupinderjit A, Bhutani MS, et al. Colorectal cancer in African Americans. Am J Gastroenterol. 2005; 100(3):515-523. discussion 514. [PubMed: 15743345]

5. Hardcastle JD, Chamberlain JO, Robinson MH, et al. Randomised controlled trial of faecal-occultblood screening for colorectal cancer. Lancet. 1996; 348(9040):1472-1477. [PubMed: 8942775]

6. Thiis-Evensen E, Hoff GS, Sauar J, Langmark F, Majak BM, Vatn MH. Population-based surveillance by colonoscopy: effect on the incidence of colorectal cancer. Telemark Polyp Study I. Scand J Gastroenterol. 1999; 34:414-420. [PubMed: 10365903]

7. Cancer Prevention \& Early Detection Facts \& Figures 2012. Atlanta: American Cancer Society; 2012. http://www.cancer.org/acs/groups/content/@epidemiologysurveilance/documents/document/ acspc-033423.pdf [Acessed June 16, 2013]

8. Subramanian S, Klosterman M, Amonkar MM, Hunt TL. Adherence with colorectal cancer screening guidelines: a review. Prev Med. 2004; 38(5):536-550. [PubMed: 15066356]

9. Higgins AY, AR BD, Phillips KL, et al. Self-reported colorectal cancer screening of Medicare beneficiaries in family medicine vs. internal medicine practices in the United States: a crosssectional study. BMC Gastroenterol. 2012; 12:23. [PubMed: 22436107]

10. Peterson SK, Verson SW. A review of patient and physician adherence to colorectal cancer screening guidelines. Semin Colon Rectal Surg. 2000; 11:58-72.

11. Powe BD, Faulkenberry R, Harmond L. A review of intervention studies that seek to increase colorectal cancer screening among African-Americans. Am J Health Promot. 2010; 25(2):92-99. [PubMed: 21039289]

12. Menon U, Belue R, Sugg Skinner C, Rothwell BE, Champion V. Perceptions of colon cancer screening by stage of screening test adoption. Cancer Nurs. 2007; 30(3):178-185. [PubMed: 17510580]

13. Rawl SM, Champion VL, Scott LL, et al. A randomized trial of two print interventions to increase colon cancer screening among first-degree relatives. Patient Educ Couns. 2008; 71(2):215-227. [PubMed: 18308500]

14. Rawl SM, Skinner CS, Perkins SM, et al. Computer-delivered tailored intervention improves colon cancer screening knowledge and health beliefs of African-Americans. Health Educ Res. 2012; 27(5):868-885. [PubMed: 22926008]

15. Prochaska, JO.; Redding, CA.; Evers, KE. The transtheoretical model and stages of change. In: Glanz, K.; Lewis, FM.; Rimer, BK., editors. Health Behavior and Health Education. San Francisco, CA: Jossey-Bass Publishers; 1997. p. 60-84.

16. Menon U, Champion VL, Larkin GN, Zollinger TW, Gerde PM, Vernon SW. Beliefs associated with fecal occult blood test and colonoscopy use at a worksite colon cancer screening program. J Occup Environ Med. 2003; 45(8):891-898. [PubMed: 12915791]

17. Vernon SW. Participation in colorectal cancer screening: a review. J Natl Cancer Inst. 1997; 89(19):1406-1422. [PubMed: 9326910]

18. Powe BD. Fatalism among elderly African Americans. Effects on colorectal cancer screening. Cancer Nurs. 1995; 18(5):385-392. [PubMed: 7585493]

19. Rakowski W, Ehrich B, Goldstein MG, et al. Increasing mammography among women aged 40-74 by use of a stage-matched, tailored intervention. Prev Med. 1998; 27(5 Pt 1):748-756. [PubMed: 9808807]

20. Chao HH, Schwartz AR, Hersh J, et al. Improving colorectal cancer screening and care in the Veterans Affairs Healthcare system. Clin Colorectal Cancer. 2009; 8(1):22-28. [PubMed: 19203893]

21. Levin B, Lieberman DA, McFarland B, et al. Screening and surveillance for the early detection of colorectal cancer and adenomatous polyps, 2008: a joint guideline from the American Cancer 
Society, the US Multi-Society Task Force on Colorectal Cancer, and the American College of Radiology. CA Cancer J Clin. 2008; 58(3):130-160. [PubMed: 18322143]

22. Champion VL, Scott CR. Reliability and validity of breast cancer screening belief scales in African American women. Nurs Res. 1997; 46(6):331-337. [PubMed: 9422052]

23. Kreuter MW, Strecher VJ. Changing inaccurate perceptions of health risk: results from a randomized trial. Health Psychol. 1995; 14(1):56-63. [PubMed: 7737074]

24. Rawl S, Champion V, Menon U, Loehrer P, Vance G, Skinner CS. Validation of scales to measure benefits and bariiers to colorectal cancer screening. J Psychosoc Oncol. 2001; 19(3/4):47-63.

25. Mayo RM, Ureda JR, Parker VG. Importance of fatalism in understanding mammography screening in rural elderly women. J Women Aging. 2001; 13(1):57-72. [PubMed: 11217186]

26. Powe BD. Cancer fatalism among elderly Caucasians and African Americans. Oncol Nurs Forum. 1995; 22(9):1355-1359. [PubMed: 8539176]

27. R Development Core Team. [Accessed June 16, 2013] R: A Language and Environment for Statistical Computing. R Foundation for Statistical Computing. 2011. http://www.r-project.org/

28. About BMI for Adults. [Accessed October 28, 2012] Centers for Diseases Control and Prevention Web site. http://www.cdc.gov/healthyweight/assessing/bmi/adult_bmi/index.html\#Why

29. Trauth JM, Ling BS, Weissfeld JL, Schoen RE, Hayran M. Using the transtheoretical model to stage screening behavior for colorectal cancer. Health Educ Behav. 2003; 30(3):322-336. [PubMed: 19731499]

30. Rawl SM, Menon U, Champion VL, et al. Do benefits and barriers differ by stage of adoption for colorectal cancer screening? Health Educ Res. 2005; 20(2):137-148. [PubMed: 15314036]

31. Lukin DJ, Jandorf LH, Dhulkifl RJ, et al. Effect of comorbid conditions on adherence to colorectal cancer screening. J Cancer Educ. 2012; 27(2):269-276. [PubMed: 22351374]

32. Manne S, Markowitz A, Winawer S, et al. Correlates of colorectal cancer screening compliance and stage of adoption among siblings of individuals with early onset colorectal cancer. Health Psychol. 2002; 21(1):3-15. [PubMed: 11846342]

33. Christie J, Jandorf L, Itzkowitz S, et al. Sociodemographic correlates of stage of adoption for colorectal cancer screening in African Americans. Ethn Dis. 2009; 19(3):323-329. [PubMed: 19769016]

34. Brittain K, Loveland-Cherry C, Northouse L, Caldwell CH, Taylor JY. Sociocultural differences and colorectal cancer screening among African American men and women. Oncol Nurs Forum. 2012; 39(1):100-107. [PubMed: 22201660]

35. Lauver DR, Henriques JB, Settersten L, Bumann MC. Psychosocial variables, external barriers, and stage of mammography adoption. Health Psychol. 2003; 22(6):649-653. [PubMed: 14640864]

36. Purnell JQ, Katz ML, Andersen BL, et al. Social and cultural factors are related to perceived colorectal cancer screening benefits and intentions in African Americans. J Behav Med. 2010; 33(1):24-34. [PubMed: 19876727]

37. Menon U, Szalacha LA, Prabhughate A. Breast and cervical cancer screening among South Asian immigrants in the United States. Cancer Nurs. 2012; 35(4):278-287. [PubMed: 21963722]

38. Griffith KA, Passmore SR, Smith D, Wenzel J. African Americans with a family history of colorectal cancer: Barriers and facilitators to screening. Oncol Nurs Forum. 2012; 39(3):299-306. [PubMed: 22543388]

39. Stoddard AM, Rimer BK, Lane D, et al. The NCI Breast Cancer Screening Consortium. Underusers of mammogram screening: stage of adoption in five U.S. subpopulations. Prev Med. 1998; 27(3):478-487. [PubMed: 9612839]

40. Menon U, Belue R, Wahab S, et al. A randomized trial comparing the effect of two phone-based interventions on colorectal cancer screening adherence. Ann Behav Med. 2011; 42(3):294-303. [PubMed: 21826576]

41. Menon U, Champion V, Monahan PO, Daggy J, Hui S, Skinner CS. Health belief model variables as predictors of progression in stage of mammography adoption. Am J Health Promot. 2007; 21(4):255-261. [PubMed: 17375491]

42. Tung WC. Benefits and barriers of pap smear screening: differences in perceptions of Vietnamese American women by stage. J Community Health Nurs. 2010; 27(1):12-22. [PubMed: 20131133] 
43. Higgins LC, Oldenburg B. Predictos of Progrssion and Regression in Exercise Adoption in Yong Women. J Appl Soc Psychol. 2003; 33(4):716-729.

44. O'Hea EL, Boudreaux ED, Jeffries SK, Carmack Taylor CL, Scarinci IC, Brantley PJ. Stage of change movement across three health behaviors: the role of self-efficacy. Am J Health Promot. 2004; 19(2):94-102. [PubMed: 15559709]

45. de Vet E, de Nooijer J, de Vries NK, Brug J. Determinants of forward stage transition from precontemplation and contemplation for fruit consumption. Am J Health Promot. 2005; 19(4): 278-285. [PubMed: 15768922]

46. Rawl SM, Menon U, Champion VL, et al. Do benefits and barriers differ by stage of adoption for colorectal cancer screening? Health Educ Res. 2005; 20(2):137-148. [PubMed: 15314036]

47. Mobley L, Kuo TM, Urato M, Boos J, Lozano-Gracia N, Anselin L. Predictors of endoscopic colorectal cancer screening over time in 11 states. Cancer Causes Control. 2010; 21(3):445-461. [PubMed: 19946738]

48. von Wagner C, Semmler C, Good A, Wardle J. Health literacy and self-efficacy for participating in colorectal cancer screening: The role of information processing. Patient Educ Couns. 2009; 75(3): 352-357. [PubMed: 19386461]

49. Rawl SM, Menon U, Burness A, Breslau ES. Interventions to promote colorectal cancer screening: An integrative review. Nurs Outlook. 2012; 60(4):172-181. e113. [PubMed: 22261002]

50. Menon U, Szalacha LA, Belue R, Rugen K, Martin KR, Kinney AY. Interactive, culturally sensitive education on colorectal cancer screening. Med Care. 2008; 46(9 Suppl 1):S44-50. [PubMed: 18725832] 


\section{Predictor Variables $\quad$ Outcome Variables}

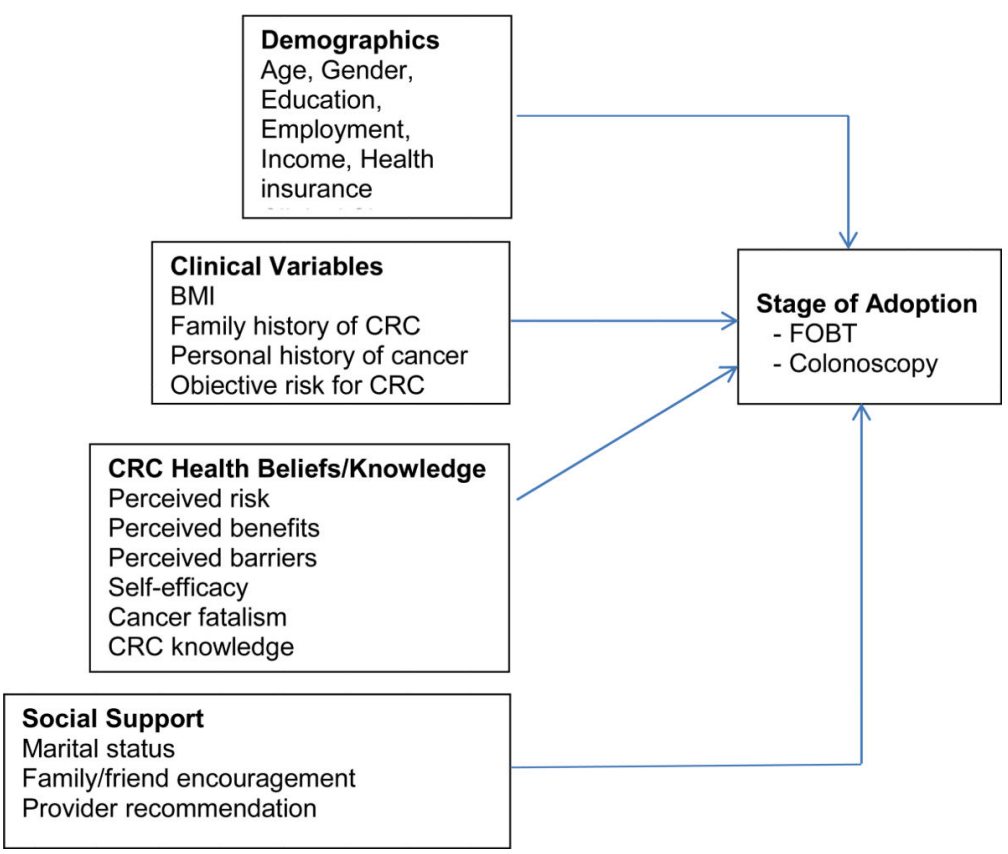

Figure. Conceptual Framework

Abbreviations: BMI, body mass index; CRC colorectal cancer; FOBT, fecal occult blood test. 
Table 1

Stage of Adoption Definitions for FOBT and Colonoscopy

\begin{tabular}{llll}
\hline CRC Screening Tests & Precontemplation & Contemplation & Preparation \\
\hline \multirow{3}{*}{ FOBT } & $\begin{array}{l}\text { Never had OR had one more than 12 } \\
\text { months ago AND does not intend to } \\
\text { have one in next 6 months. }\end{array}$ & $\begin{array}{l}\text { Never had OR had one more than } \\
12 \text { months ago AND intends to } \\
\text { have one in next 6 months. }\end{array}$ & $\begin{array}{l}\text { Never had OR had one more than } \\
12 \text { months ago, is planning to do in } \\
\text { next six months, and has an FOBT } \\
\text { kit. }\end{array}$ \\
Colonoscopy & $\begin{array}{l}\text { Never had OR had one more than 10 } \\
\text { years ago AND does not intend to have } \\
\text { one in next 6 months. }\end{array}$ & $\begin{array}{l}\text { Never had OR had one more than } \\
\text { 10 years ago AND intends to have } \\
\text { one in next 6 months. }\end{array}$ & $\begin{array}{l}\text { Never had OR had one more than } \\
10 \text { years ago, is planning to do in } \\
\text { next six months, and has an } \\
\text { appointment scheduled. }\end{array}$ \\
\hline
\end{tabular}

Abbreviations: CRC colorectal cancer; FOBT, fecal occult blood test. 


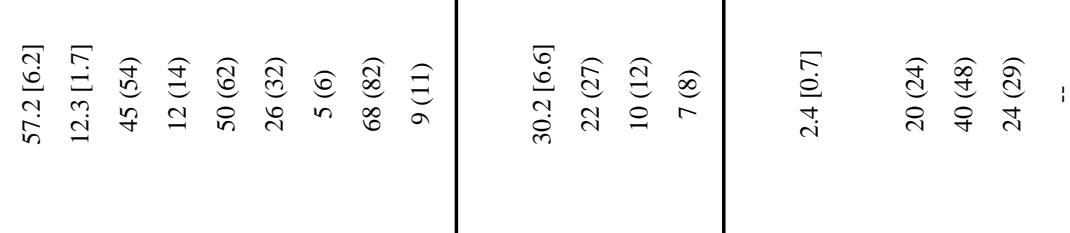

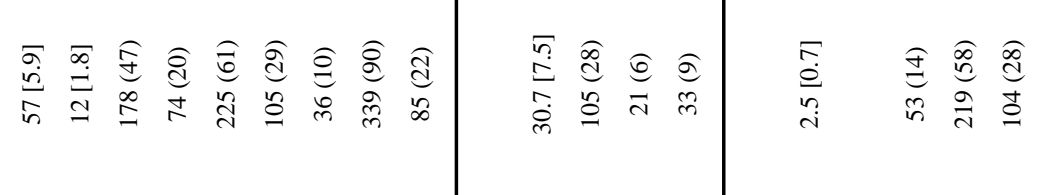

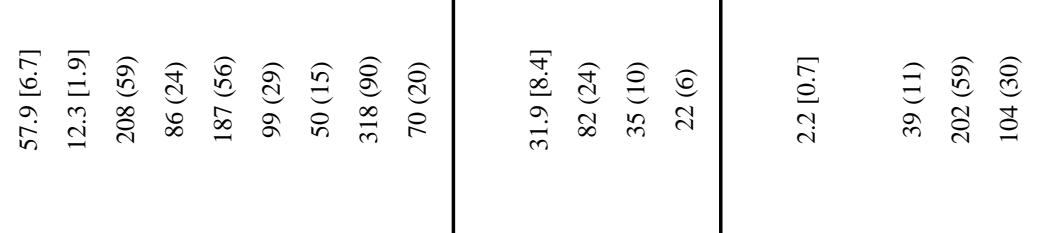

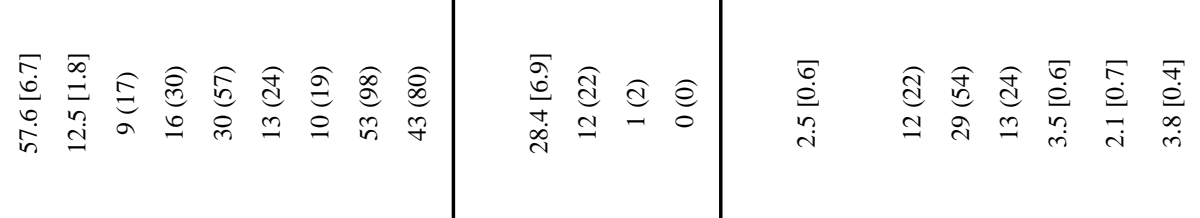

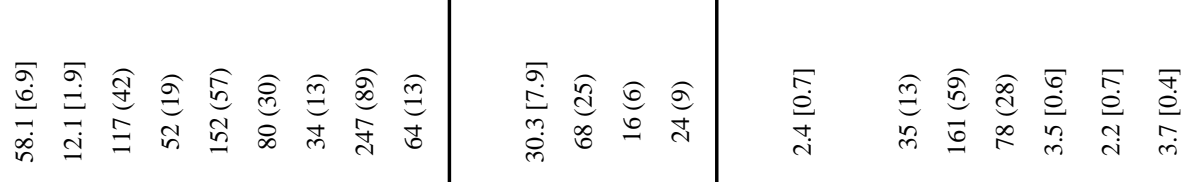

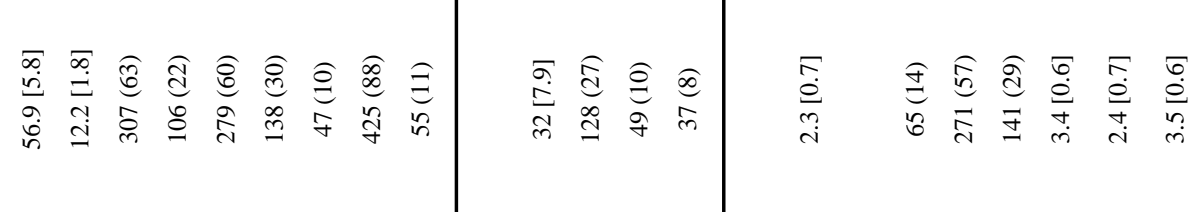

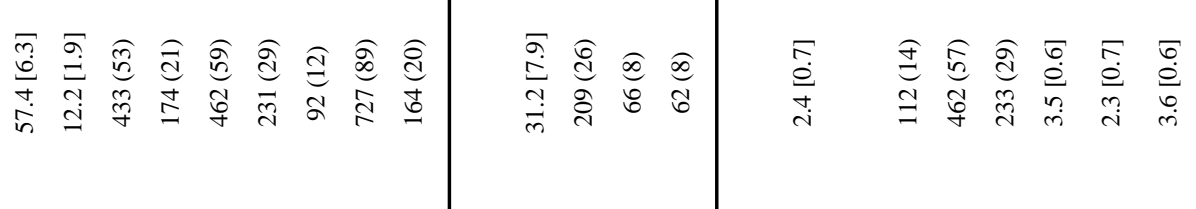

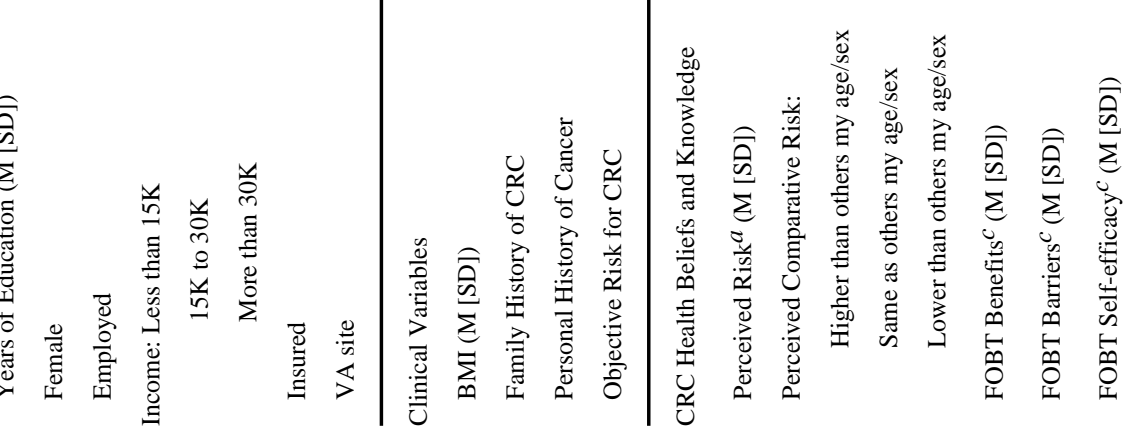


Table 3

Predictors of Stage of Adoption for FOBT from Hierarchical Modeling ${ }^{a}$

\begin{tabular}{|c|c|c|c|c|}
\hline \multirow[t]{2}{*}{ Predictor Variables $b$} & \multicolumn{4}{|c|}{ FOBT Stage of Adoption } \\
\hline & $\begin{array}{c}\text { Step 1 } \\
\text { OR }(\mathbf{9 5 \%} \text { CI })\end{array}$ & $\begin{array}{c}\text { Step 2 } \\
\text { OR }(\mathbf{9 5 \%} \text { CI })\end{array}$ & $\begin{array}{c}\text { Step 3 } \\
\text { OR }(\mathbf{9 5 \%} \text { CI })\end{array}$ & $\begin{array}{c}\text { Step } 4 \\
\text { OR }(95 \% \mathrm{CI})\end{array}$ \\
\hline \multicolumn{5}{|l|}{ Demographics } \\
\hline Age & $1.04(1.10-1.06)^{* *}$ & $1.04(1.01-1.06)^{* *}$ & $1.04(1.01-1.06)^{* *}$ & $1.04(1.01-1.06)^{* *}$ \\
\hline Male & $1.86(1.32-2.63)^{* *}$ & $1.68(1.17-2.41)^{* *}$ & $1.72(1.19-2.48)^{* *}$ & $1.70(1.16-2.49)^{* * *}$ \\
\hline Income: $15 \mathrm{~K}-30 \mathrm{~K}$ vs. $<15 \mathrm{~K}$ & $0.97(0.69-1.35)$ & $0.98(0.70-1.37)$ & $0.90(0.64-1.27)$ & $0.82(0.57-1.16)$ \\
\hline$>30 \mathrm{~K}$ vs. $<15 \mathrm{~K}$ & $1.15(0.73-1.83)$ & $1.23(0.77-1.96)$ & $1.06(0.66-1.07)$ & $1.03(0.63-1.69)$ \\
\hline Insurance & $1.00(0.62-1.63)$ & $1.01(0.62-1.66)$ & $1.01(0.62-1.67)$ & $0.94(0.57-1.57)$ \\
\hline VA site & $3.77(2.47-5.77)^{* *}$ & $3.92(2.56-6.02)^{* *}$ & $3.46(2.25-5.34)^{* *}$ & $2.80(1.76-4.44)^{* * *}$ \\
\hline \multicolumn{5}{|l|}{ Clinical Variables } \\
\hline BMI & & $0.98(0.96-1.00)$ & $0.99(0.97-1.01)$ & $0.98(0.96-1.01)$ \\
\hline Personal History of Cancer & & $0.38(0.20-0.71)^{* *}$ & $0.38(0.20-0.71)^{* *}$ & $0.37(0.19-0.70)^{* *}$ \\
\hline \multicolumn{5}{|l|}{ CRC Health Beliefs \& Knowledge } \\
\hline Perceived Risk & & & $1.05(0.92-1.20)$ & $1.06(0.92-1.21)$ \\
\hline FOBT Benefits & & & $1.20(0.92-1.56)$ & $1.15(0.88-1.50)$ \\
\hline FOBT Barriers & & & $0.79(0.63-0.98)^{*}$ & $0.79(0.63-0.99)^{*}$ \\
\hline FOBT Self-efficacy & & & $1.79(1.28-2.49)^{* *}$ & $1.59(1.13-2.23)^{* * *}$ \\
\hline \multicolumn{5}{|l|}{ Social Support } \\
\hline Married/Partnered & & & & $1.23(0.88-1.72)$ \\
\hline Family/friend Encouragement & & & & $1.64(1.18-2.29)^{* *}$ \\
\hline Provider Recommendation & & & & $2.05(1.48-2.85)^{* *}$ \\
\hline Generalized $\mathrm{R}^{2}$ & 0.126 & $0.140^{* *}$ & $0.169^{* *}$ & $0.202 * *$ \\
\hline
\end{tabular}

Abbreviations: BMI, body mass index; CI, confidence interval; CRC, colorectal cancer; FOBT, fecal occult blood test; K, thousand; OR, odds ratio.

$a_{*} p<.05, * * p<.01$

${ }^{b}$ Variables with $p \leq 2$ from the bivariate analysis. 
Table 4

Predictors of Stage of Adoption for Colonoscopy from Hierarchical Modeling ${ }^{a}$

\begin{tabular}{|c|c|c|c|c|}
\hline \multirow[t]{2}{*}{ Predictor Variables $b$} & \multicolumn{4}{|c|}{ Colonoscopy Stage of Adoption } \\
\hline & $\begin{array}{c}\text { Step 1 } \\
\text { OR }(95 \% \text { CI })\end{array}$ & $\begin{array}{c}\text { Step 2 } \\
\text { OR }(95 \% \text { CI })\end{array}$ & $\begin{array}{c}\text { Step 3 } \\
\text { OR }(95 \% \text { CI })\end{array}$ & $\begin{array}{c}\text { Step } 4 \\
\text { OR }(95 \% \text { CI })\end{array}$ \\
\hline \multicolumn{5}{|l|}{ Demographics } \\
\hline Age & $0.98(0.96-1.00)$ & $0.98(0.96-1.00)^{* *}$ & $0.99(0.96-1.01)$ & $0.98(0.96-1.00)$ \\
\hline Education & $0.97(0.90-1.05)$ & $0.97(0.90-1.05)$ & $0.95(0.88-1.03)$ & $0.95(0.88-1.04)$ \\
\hline Male & $1.50(1.14-1.97)^{* *}$ & $1.37(1.02-1.83)^{* *}$ & $1.27(0.94-1.71)$ & $1.29(0.95-1.75)$ \\
\hline Income: $15 \mathrm{~K}-30 \mathrm{~K}$ vs. $<15 \mathrm{~K}$ & $0.98(0.72-1.33)$ & $0.97(0.72-1.33)$ & $0.86(0.63-1.18)$ & $0.83(0.60-1.14)$ \\
\hline Income: $>30 \mathrm{~K}$ vs. $<15 \mathrm{~K}$ & $0.56(0.35-0.89)^{* *}$ & $0.57(0.36-0.90)^{*}$ & $0.47(0.29-0.75)^{* *}$ & $0.46(0.28-0.75)^{* *}$ \\
\hline Insurance & $1.34(0.87-2.07)$ & $1.43(0.92-2.23)$ & $1.57(1.00-2.47)^{*}$ & $1.47(0.94-2.32)$ \\
\hline \multicolumn{5}{|l|}{ Clinical Variables } \\
\hline BMI & & $0.98(0.97-1.02)$ & $0.98(0.88-1.03)$ & $0.98(0.96-1.00)$ \\
\hline \multicolumn{5}{|l|}{ CRC Health Beliefs \& Knowledge } \\
\hline Perceived Risk & & & $1.12(0.98-1.29)$ & $1.12(0.97-1.28)$ \\
\hline \multicolumn{5}{|l|}{ Perceived Comparative Risk: } \\
\hline Higher vs. Same as others & & & $1.65(1.09-2.51)^{*}$ & $1.47(0.96-2.25)$ \\
\hline Lower vs. Same as others & & & $1.02(0.74-1.14)$ & $1.08(0.78-1.51)$ \\
\hline Colonoscopy Benefits & & & $1.52(1.21-1.92)^{* *}$ & $1.56(1.23-1.98)^{* *}$ \\
\hline Colonoscopy Barriers & & & $0.89(0.73-1.10)$ & $0.88(0.71-1.08)$ \\
\hline Colonoscopy Self-efficacy & & & $1.77(1.34-2.35)^{* *}$ & $1.66(1.25-2.22)^{* *}$ \\
\hline \multicolumn{5}{|l|}{ Social Support } \\
\hline Family/friend Encouragement & & & & $1.71(1.23-2.36)^{* *}$ \\
\hline Provider Recommendation & & & & $2.47(1.84-3.33)^{* *}$ \\
\hline Generalized $\mathrm{R}^{2}$ & 0.026 & $0.032^{* *}$ & $0.098^{* *}$ & $0.162 * *$ \\
\hline
\end{tabular}

Abbreviations: BMI, body mass index; CI, confidence interval; CRC, colorectal cancer; K, thousand; OR, odds ratio.

$a_{* p<.05, * * p<.01}$

${ }^{b}$ Variables with $p \leq 2$ from the bivariate analysis. 